\title{
Adolescer em corpo, mente e afeto: um estudo sobre desenvolvimento de valores e atitudes a partir do Ensino de Ciências
}

Gabriela Messias Silva*, José Adriano Cavalcante Angelo**, Jemima Queiroz da Silva***

\section{Resumo}

Os Parâmetros Curriculares Nacionais (PCNs) do Terceiro e Quarto Ciclos do Ensino Fundamental das Ciências Naturais referenciam ações educativas que significam a adolescência considerando a necessária interação entre a marca orgânica, a puberdade, e os sentidos produzidos cultural e socialmente sobre o corpo e a identidade nesta fase do desenvolvimento humano. À docência em Ciências implica na construção relacional de conhecimentos, valores e atitudes para um adolescer que responda às demandas sobre si, de modo crítico, cognitiva e afetivamente, para manutenção da integridade corporal, da saúde reprodutiva e do comportamento sexual. Esta pesquisa teve por objetivo analisar os alcances das ações e práticas na educação em Ciências na adolescência a partir do conteúdo da fala de estudantes do $9^{\circ}$ Ano. Para isso utilizou-se como método de coleta de dados, o Grupo Focal e como instrumento de análise, a Análise do Conteúdo proposta por Bardin. Emergiram três categorias: na primeira, o fator gênero é tomado como referência para indicar as variações de autoimagem e autovalor atribuídos a si mesmos pelos adolescentes; na segunda, autoavaliação da aparência física está relacionada aos padrões culturais de beleza e de ideal do corpo, recaindo sobre os seus valores e julgamentos, potencializando sentimentos de inadequação pela não correspondência às expectativas do modelo predominante; e a terceira, assinala a ausência de uma fonte segura na escola para tomada de decisões. A pesquisa concluiu, neste contexto, que a escola não é um lugar de fala para o adolescente, por tratar de temas ligados a adolescência com impessoalidade, centrandose no viés biológico da puberdade e negligenciando as questões psicossociais, emocionais e culturais que o adolescer demanda.

Palavras-chave: adolescência; cultura; Educação em Ciências; puberdade; subjetividade.

* Graduada em Licenciatura em Ciências Biológicas pela UFT, Brasil. E-mail: gabriela-messias97@hotmail.com

** Mestre em Educação pela UFPB, Graduado em Licenciatura em Ciências Biológicas pela UFPB, Brasil. E-mail: adriano.angelo@gmail.com

*** Mestra em Educação pela UFPB, Graduada em Psicologia (Formação de Psicólogo e Licenciatura) pela UFPB. Professora da UFT, Brasil. E-mail: jemima@uft.edu.br

Recebido em: 06/08/2020; Aceito em: 21/02/2021

https://doi.org/10.5335/rbecm.v4i2.11222

http://creativecommons.org/licenses/by-nc-nd/4.0

ISSN: 2595-7376 


\section{Introdução}

Adolescer em corpo, mente e afeto implica caracterizar a adolescência como um conceito produto do contexto histórico, social, econômico e cultural do século XX (MEAD, 1970; ARIÈS, 1981). Definida como uma fase do desenvolvimento humano em que se processam definições identitárias, valorativas, emocionais, relacionais e comportamentais, deve ser compreendida considerando a associação da sua marca orgânica de mudanças na anatomia e fisiologia, que é a puberdade, com as mudanças comportamentais (AGUIAR, 2014).

Por sua complexidade biológica e psicossocial, a adolescência demanda qualidade das ações pedagógicas do processo educativo na escola ao se tratar da relação indivíduo cultura em distintas condições objetivas de vida desta fase. Isto no sentido de ultrapassar marcadores sociais que tendem a homogeneizar a adolescência, universalizando significados de ser e de estar adolescente (CERQUEIRA-SANTOS; MELO NETO; KOLLER, 2014).

A docência em Ciências e Biologia, nesta tarefa de mediar de forma gradual, ativa e crítica, os estudantes para uma vida cidadã, fundamenta as práticas educativas na dinâmica do desenvolvimento físico, cognitivo e social do ser humano, valendo-se para isto de parâmetros nacionais, que referenciam a adolescência na interface entre o desenvolvimento biológico do corpo adolescente e os alcances subjetivos deste processo.

Os Parâmetros Curriculares Nacionais (PCNs) (1998) do Terceiro e Quarto Ciclos do Ensino Fundamental das Ciências Naturais apresentam conceitos acerca do ser humano e da saúde. As propostas orientam a abordagem de assuntos atuais e relevantes sobre o desenvolvimento do ser humano, nas suas diferentes fases, com o objetivo de que o estudante compreenda não apenas as funções de cada parte do seu corpo, mas a preservação da sua saúde e bem-estar físico, mental e relacional. Para este ciclo, são temáticas de ensino: a capacidade de raciocínio por parte do cérebro humano, a sua capacidade de processar e elaborar respostas para os estímulos provocados ao cérebro humano desencadeando emoções, comportamentos e hábitos (BRASIL, 1998).

Como parte do matiz desta ampla mediação educativa em Ciências, evidenciam-se o campo sociológicos que dá suporte a perspectiva dos corpos adolescentes como elementos culturais, e o campo da Psicologia do Desenvolvimento (BEE; BOYD, 
2011; PAPALIA; FELDMAN, 2013), no que se refere a importância do esclarecimento das transformações biológicas e sociais aos jovens, pois, as mudanças “dramáticas nas estruturas cerebrais envolvidas nas emoções, no julgamento, organização do comportamento e autocontrole ocorrem entre a puberdade e o início da vida adulta” (PAPALIA; FELDMAN, 2013, p. 392).

Considerando esta relevância dos alcances da Educação em Ciências para a formação humana multidimensional, este trabalho analisou os alcances das ações e práticas no Ensino de Ciências na promoção de conhecimentos, valores e atitudes na adolescência a partir do conteúdo da fala de estudantes.

Nesta investigação, coletou-se dados em dois Grupos Focais compostos por estudantes do 9ํㅡㄹ Ano do Ensino Fundamental Séries Finais. O conteúdo das falas dos grupos foi transcrito e tratado utilizando o método da Análise de Conteúdo de Laurence Bardin, baseado na unidade de análise “O Tema” (BARDIN, 2016, p. 105). Daí surgiram três categorias analisadas e discutidas à luz da fundamentação teórica da pesquisa. São elas: Autoimagem, autoestima e fatores de variação, Assimetria do lugar social do corpo adolescente e $O$ valor da fonte segura na tomada de decisão.

\section{Fundamentação teórica}

Em uma análise sobre a formação do indivíduo e a transformação dos conceitos de criança e sua relação com a sociedade, verifica-se que nas sociedades pré-industriais as crianças eram vistas como adultos em miniatura e somente a partir do século XX, no mundo ocidental, se compreendeu a infância e adolescência como estágios separados.

Na contemporaneidade, com o aumento da globalização, da facilidade e rapidez na comunicação há uma modificação na relação do jovem com o mundo, uma conexão entre os jovens de todo o mundo, a adolescência deixa de ser um fenômeno ocidental e desencadeia mudanças sociais ao redor de todo o mundo, necessitando de maior escolaridade e informação sobre a vida adulta e as responsabilidades com o trabalho (PAPALIA; FELDMAN, 2013).

De acordo com Papalia e Feldman (2013), a adolescência não é vista da mesma maneira em todas as partes do mundo, há uma interconexão e uma interdependência. Portanto, “[...] a adolescência não é a mesma no mundo todo. A mão forte da cultura 
molda seu significado diferentemente em diferentes sociedades" (p. 388). Além do que, muitos países ou culturas têm ritos de passagem da infância para a adolescência.

Considerando que cada jovem tem seu tempo e ritmo de desenvolvimento social, físico, cognitivo e afetivo é de suma importância o acompanhamento e orientação dos profissionais da escola, pois o comportamento do jovem e suas decisões refletem sua relação com os pais, o grupo de amigos, com a sociedade e principalmente consigo mesmo.

\section{Adolescer em corpo}

As mudanças do corpo provenientes de modificações anatômicas e fisiológicas denominadas de puberdade, configuram-se pelo surgimento das características sexuais secundárias, assim,

1.Nos meninos: modificação no timbre da voz; aumento da largura dos ombros; aparecimento de pelos no rosto, axilas e região pubiana; crescimento do pênis e testículos; e o surgimento da primeira ejaculação.

2. Nas meninas: desenvolvimento das glândulas mamárias; aumento dos quadris; aparecimento de pelos na região pubiana; e o surgimento da primeira menstruação, chamada menarca (AMARAL, 2007, p. 4).

Este critério biológico, segundo Campos (2012), não implica em um marco inicial da adolescência, pois os fatores intrínsecos do indivíduo é que devem servir de norteadores já que idade cronológica não corresponde diretamente a idade biológica.

Neste trabalho, entende-se a adolescência como "um termo sociológico que, sob uma suposta base biológica, tornou-se de uso psicológico” (STEVENS, 2004, p. 27). Estabelece-se assim, o entendimento que adolescência se refere as "[...] reações psicológicas do jovem a suas mudanças físicas da puberdade e se prolonga até uma razoável resolução de sua identidade pessoal” (CAMPOS, 2012, p. 15).

A importância em se definir e reflexionar os alcances subjetivos que as transformações do corpo e no corpo podem provocar na adolescência deve-se a sua abrangência também aos processos educativos na escola - qualidade das relações interpessoais, desempenho acadêmico, motivação para iniciar e manter atividades escolares.

A auto avaliação da aparência física tem correspondências as normas culturais de beleza e de ideal do corpo, influenciando os valores e julgamentos sobre si, po- 
dendo gerar sentimentos de inadequação pela não correspondência às expectativas do modelo dominante (SHAFFER; KIPP, 2012).

Esse corpo adolescente cheio de novos significados traz impactos psicológicos importantes que subsidiarão uma (re)constituição de sua imagem no desenvolvimento da identidade. Segundo Stice e Whitenton (2002), sentimentos positivos acerca do corpo possibilitam ao adolescente elevada autoestima e positividade nas relações no grupo de iguais.

A insatisfação com a imagem do corpo varia em meninos e meninas. Para os meninos, há a categoria dos que anseiam por perder peso e aquela, cujo desejo é terem um corpo musculoso. Entende-se que, para aqueles que estão com o peso acima da média, a insatisfação aumenta com o aumento do peso e, para aqueles que estão com o peso abaixo da média, o descontentamento é maior quanto menor for o seu peso (KOSTANSKI; FISHER; GULLONE, 2004). De acordo com Presnell et al.(2004), as meninas se sentem obrigadas a se manterem magras e a falta de apreço pela imagem do corpo está relacionada a estética da magreza, sentem-se insatisfeitas com o corpo independentemente do peso real.

Essas especificidades acerca da imagem corporal ideal são elementos fundamentais no processo de desenvolvimento humano na adolescência e pode indicar fatores de risco de transtornos alimentares, como anorexia e bulimia, e ainda depressão, refletindo sobre os processos educacionais. Isso porque "[...] é em torno desse ideal corporal que o adolescente vai se estruturando: entre o corpo temido e desconhecido, e o corpo perfeito e idealizado [...]” (CALHEIROS SANTOS; ZANOTTI, 2013, p. 1).

A percepção que o adolescente “[...] tem de si mesmo nos mais diversos aspectos da vida [...]” (OLIVEIRA, 2015, p. 5), denomina-se de autoconceito vai e influenciar "[...] o universo de representações que o estudante tem das suas capacidades, das suas realizações escolares, bem como as avaliações que ele faz dessas mesmas capacidades e realizações” (SILVA; VENDRAMINI, 2006, p. 179).

Trata-se de uma estrutura cognitiva de crenças que a pessoa tem acerca de sua imagem e das capacidades pessoais em realizar tarefas nas mais diversas áreas da vida. E essa imagem de si próprio, no que se refere a adequação ou inadequação do corpo, reverbera em aspectos avaliativos e organizativos para tomar decisões e escolher comportamentos.

Tomando como referência Shavelson e Bolus (1982), pode-se afirmar que as avaliações feitas pelas pessoas significativas da vida do adolescente, fornecem as 
bases de percepção sobre seu comportamento, “[...] neste aspecto admite-se que o ser humano é levado a desenvolver uma espécie de fenómeno de espelho, em que tende a observar-se da maneira como os outros o consideram [...]" (VAZ-SERRA, 1988, p. 101).

Considera-se então, o papel docente em mediar e facilitar processos e experiências com feedbacks positivos e realistas do corpo adolescente nos aspectos relacionais, de valores, habilidades e atitudes, dos direitos humanos, da imagem e integridade corporal, da saúde reprodutiva e do comportamento sexual.

\section{Adolescer em mente}

Para compreender o desenvolvimento humano, principalmente entre os jovens é de suma importância estudar os aspectos cognitivos e a formação dos seus pensamentos. Papalia e Feldman (2013) falam sobre o estágio operatório formal de Piaget, as mudanças no processamento das informações, o desenvolvimento da linguagem, o raciocínio moral (teoria de Kohlberg).

O estágio operatório formal descrito por Piaget (2012) é considerado quando o indivíduo compreende além do aqui e do agora, quando conseguem pensar de forma abstrata, entende as representações e os símbolos, imaginam possibilidades e hipóteses. Essa maneira de pensar é percebida geralmente por volta de onze a quinze anos.

O acesso à informação e as experiências individuais contribuem de forma significativa para o desenvolvimento cognitivo da criança. Diversos pesquisadores descrevem a existência de duas categorias nas mudanças do pensamento adolescente, a mudança estrutural e a mudança funcional. Um estudo sobre a mudança estrutural realizado por Eccles, Wigfield e Byrnes, (2003), inclui o aumento da capacidade de memorização, de lidar com problemas e a tomada de decisões, pode ser dividida em conhecimento declarativo (saber que...), conhecimento procedural (saber como...) e o conhecimento conceitual (saber por que...). Já a mudança funcional é descrita como os processos de obtenção, manipulação e retenção de informações para consequentemente possam aprender, lembrar e raciocinar.

O desenvolvimento da linguagem é outro aspecto que expressa o nível de desenvolvimento cognitivo. Há o aumento do vocabulário de acordo com as leituras feitas e a utilização do pensamento abstrato, de tal modo que os adolescentes "[...] tornam-se mais conscientes das palavras como símbolos que podem ter múltiplos 
significados; e têm prazer em usar ironias, trocadilhos e metáforas” (PAPALIA; FELDMAN, 2013, p. 407).

Um outro aspecto do adolescer em mente é o desenvolvimento do raciocínio moral. Kohlberg (1992), apresenta um estudo baseado nas ideias de Piaget acerca do desenvolvimento moral dos indivíduos, neste, é possível identificar três níveis e seis estágios que representam as formas que os indivíduos lidam com um dilema moral. No nível 1, Moralidade pré-convencional, a moralidade está vinculada a obediência com medo da punição; no nível 2, Moralidade convencional, caracterizado pela observação as normas sociais do grupo e posteriormente das normas e leis gerais; e, nível 3, Moralidade pós-convencional, cuja premissa são os princípios éticos universais (PAPALIA; FELDMAN, 2013).

Entende-se assim que, as formas de pensar a moral e lidar com a resolução de conflitos se modifica ao longo dos anos de acordo com as experiências das crianças e adolescentes com os pais, o grupo de amigos, as experiências na escola e de acordo com suas culturas, ou seja, o contato com mundo que estão inseridos.

Caracterizar o desenvolvimento cognitivo do adolescente é considerar também as mudanças no processamento da informação em termos de velocidade e qualidade, uma vez que é neste período do desenvolvimento humano que os recursos cognitivos podem ser controlados intencionalmente, e isto implica em "[...] maior probabilidade de ter em mente diversas dimensões de um tema ou de um problema simultaneamente, enquanto que os mais jovens têm maior tendência a focarem em apenas uma dimensão" (SANTROCK, 2014, p. 128).

Assim, em termos de funcionamento executivo na adolescência, a metacognição e os processos cognitivos de alta complexidade como a tomada de decisão, controle cognitivo, pensamento flexível e o pensamento crítico passam a emergir pela maturação dos circuitos cerebrais a assumem qualidade nas experiências pessoais e interpessoais no meio social.

Compreender o desenvolvimento cognitivo em toda sua amplitude auxilia o entendimento acerca dos comportamentos do adolescente na exposição aos riscos, nos julgamentos, na autorregulação das aprendizagens e na formação de seus posicionamentos críticos frente as demandas atitudinais, educacionais, relacionais e afetivas. 
Henri Wallon (1995), assume uma abordagem do desenvolvimento humano baseada na interdependência dos fatores biológicos, atributos pessoais e condições de existência concebendo uma psicogênese da pessoa completa nas dimensões afetiva, cognitiva e motora.

Isto implica em rejeitar as conexões biológicas como única explicação para as expressões e respostas afetivas humanas. Segundo o autor, a estrutura orgânica para se desenvolver necessita das intervenções culturais para avançar, num funcionamento dialético, em ritmo próprio por meio de estágios não lineares.

As emoções pertencem a um meio diferente do meio puramente físico; é outro plano em que elas fazem sentir seus efeitos. Sua natureza resulta expressamente de um traço que lhes é essencial: sua extrema contagiosidade de indivíduo a indivíduo. Elas implicam relações interindividuais; dependem de relações coletivas; o meio que lhes corresponde é o dos seres vivos (WALLON, 1995, p. 122).

As pressões da sociedade, as transformações do corpo e da mente, o contato com diferentes pessoas, a fase de experimentação, as incertezas, o medo do contato social, ansiedade, estar sob estresse, conflitos familiares, abuso de drogas, e ter o histórico de depressão entre os pais dentre outros fatores, ameaçam a dimensão afetiva dos adolescentes. Então,

[...] é possível pensar a afetividade como um processo amplo que envolve a pessoa em sua totalidade. Na constituição da estrutura da afetividade, contribuem de forma significativa as diferentes modalidades de descarga do tônus, as relações interpessoais e a afirmação de si mesmo, possibilitada pelas atividades de relação (WALLON, 1995, p. 14).

Por isso mesmo, para além dos professores e as instruções em sala de aula, é necessário também uma relação entre os indivíduos (crianças/adolescentes) e os pais, que também devem orientar seus filhos. Esta é a ideia defendida por Youngblade $e t$ al. (2007), a de que o crescimento não é só em termos físicos, mas também cognitivo, social e afetivo, onde se desenvolve a autonomia e a autoestima, uma vez que os jovens que têm relações de apoio com os pais, a escola e a comunidade tendem a desenvolver-se de forma positiva e saudável. Nesse estudo, os autores distinguem apenas as famílias em biparentais e monoparentais, sem referenciar o gênero da organização familiar. Já os que não recebem apoio e instrução, segundo Eaton et 
al. (2008) têm o seu bem-estar físico e metal postos em risco, com elevadas taxas de mortalidade devido a acidentes, homicídios e suicídios.

Na adolescência, o relacionamento entre os pais e os filhos passam por algumas fragilidades, as etapas de desenvolvimento são contraditórias, pois, ao mesmo tempo que devem se tornar independentes, também devem estabelecer uma relação com os pais, causando assim uma pressão por autonomia e um conflito na manutenção da conexão/apego aos pais (BEE; BOYD, 2011).

As relações sociais do adolescente na escola e na família permitem a estruturação de sua afetividade pelo espaço social dada as oportunidades de expressões pessoais de existência. Daí a relevância em se considerar a aprendizagem como uma ação complexa de recepção psíquica de construção única. Então aos adultos, figuras representativas na vida do adolescente, sejam pais ou professoras e professores devem evitar reduzir as expressões adolescentes a campos independentes de ação.

Ao ambiente escolar, deve-se conceber a afetividade como mobilizadora da inteligência, de tal modo que as expressões da subjetividade estejam conectadas ao processo de aprendizagem. A pessoa que aprende, o adolescente aprendente deve ser conhecido em todas as suas dimensões, compreendido em todas sua complexidade e incluídos em atividades compatíveis com sua completude. Wallon (1995, p. 42) considera

[...] o caráter 'contagioso' dos estados emocionais, o professor pode manter-se mais atento ao clima de grupo que ele tem condições de estabelecer em sua turma de alunos, bem como à importância de suas próprias manifestações afetivas, que, seguramente, incidirão nas crianças sob sua tutela. Queremos dizer, portanto, que não se trata de buscar o controle das condições em sala de aula a partir da coerção das manifestações expressivas dos alunos, mas da melhor compreensão de seu significado para um manejo que, incorporando a dimensão afetiva, possibilite uma melhor qualidade e aproveitamento da aprendizagem.

Portanto, as ações educativas escolares na perspectiva da pessoa completa, devem possibilitar ao professor compreender-se como unidade relacional com o aprendente, ciente do papel de facilitador da individuação, pois, ao "[...] incluir em suas decisões não só considerações relativas ao cognitivo, mas também seu impacto sobre o motor e o afetivo" (MAHONEY, 2010, p. 10), potencializa a busca de novos sentido e qualifica a percepção avaliativa sobre si mesmo. 


\section{Adolescer em perspectiva curricular no Ensino de Ciências}

Considerando a escola como o primeiro espaço de educação formal, responsável pela orientação dos alunos de forma gradual, ativa e crítica, faz-se necessário o estudo dos documentos oficiais que orientam as ações pedagógicas que considerem a dinâmica do desenvolvimento físico, cognitivo e social do ser humano.

Os Parâmetros Curriculares Nacionais (1998) do Terceiro e Quarto Ciclos do Ensino Fundamental no campo das Ciências Naturais apresentam conceitos acerca do ser humano e da saúde para que assim os docentes possam compreender e ter como base as orientações citadas neste para preparação de suas aulas.

Os PCNs (BRASIL, 1998, p. 102) apresentam algumas propostas que possam explicar os assuntos atuais e relevantes sobre a instrução e o desenvolvimento do ser humano, nas suas diferentes fases, para que este seja capaz de preservar sua saúde e entender as funções de cada parte do seu corpo. Propõe a criação de folhetos, textos coletivos, comunicação de informações, a apresentação de tabelas, atlas anatômicos, experimentos e simulações, entre outros.

Compreender a existência do ser humano requer também entender o espaço que está inserido e os demais agentes envolvidos na sua evolução, ou seja, estudar os demais seres vivos. É sugerido pelos PCNs (BRASIL, 1998, p. 103) que os alunos saibam a função da respiração celular dos seres vivos e como funciona o processo de obtenção de energia, seja pelas bactérias ou fungos nas plantas e animais, compreendendo-se também o processo de fotossíntese (utilização da luz e liberação de oxigênio).

É importante que os alunos entendam também a relação entre sensação e emoção, os processos e funções reguladoras do sistema nervoso e glandular, para que isso aconteça é necessária uma orientação e coordenação do professor, como é possível ler nos PCNs:

Quanto às funções reguladoras, os estudantes poderão investigar, novamente com a coordenação e ajuda do professor, processos ligados à equilibração do organismo e à locomoção voluntária, à circulação e respiração, processos regulados e controlados pelos sistemas nervoso e glandular, intimamente ligados às percepções sensoriais e às emoções (BRASIL, 1998, p. 103). 
Concebendo assim a integração entre os mais diferentes sistemas do corpo e a influência que cada uma desempenha sobre a outra, as ações e reações bem como o equilíbrio entre estas (BRASIL, 1998, p. 103).

É possível perceber então as similaridades e diferenças entre o ser humano e os outros seres vivos presentes na natureza, uma das diferenças citadas nos PCNs (1998) é a capacidade de raciocínio por parte do cérebro humano, a sua “[...] capacidade de processar e responder [...]” estímulos provocados ao cérebro humano desencadeando emoções, comportamentos e hábitos (BRASIL, 1998, p. 104). Sendo assim,

O contexto de estudos do cérebro, da mente humana, também é o campo dos comportamentos, das emoções, da formação dos hábitos e de outras questões subjetivas, ligadas aos valores, de modo ainda mais evidente que em outros estudos do ser humano (BRASIL, 1998, p. 104).

Faz-se necessário entender então, como é o desenvolvimento do cérebro humano, quando este está totalmente desenvolvido e quando ainda está passando pelo processo de maturação, considerando os PCNs (1998) e os estudos de Papalia e Feldman (2013) percebemos a importância do esclarecimento das transformações biológicas e sociais para os jovens, pois, diferente do que se acreditava anteriormente, que na puberdade o cérebro já havia se desenvolvido totalmente, entende-se agora que, as mudanças "[...] dramáticas nas estruturas cerebrais envolvidas nas emoções, no julgamento, organização do comportamento e autocontrole ocorrem entre a puberdade e o início da vida adulta [...]” (PAPALIA; FELDMAN, 2013, p. 392).

Então, no sentido de abordar os modos de vida do indivíduo, sugere-se que os estudantes sejam informados sobre os riscos no comportamento e as consequências dos seus atos, como por exemplo, o envolvimento com a violência devido ao consumo de drogas (álcool, barbitúricos, tranquilizantes, antidepressivos e narcóticos), e também a gravidez indesejada na adolescência (BRASIL, 1998).

Daí a importância da orientação aos jovens, pois o desenvolvimento do cérebro é bidirecional e baseado no estímulo cognitivo que ele é submetido ao longo de sua formação, de forma que as atividades e experiências vividas pelos adolescentes são os seus fatores determinantes (KUHN, 2006). Ou seja, quando o jovem é estimulado a pensar ordenadamente e controlar os impulsos, ele continuará agindo desta forma também quando chegar a vida adulta.

Entende-se a relevância da abordagem pelos professores também de alguns temas polêmicos, apresentando as informações necessárias, bem como, discutir os 
valores envolvidos nas atitudes tomadas, ressaltando que os atos são voluntários, o corpo é uma totalidade e o desequilíbrio em determinado ponto abala o equilíbrio da totalidade (BRASIL, 1998).

Tendo por princípio o corpo humano, é possível identificar nos PCNs (1998) inúmeros aspectos da formação deste, a respiração, geração e distribuição de energia, sistema nervoso e glandular, os estímulos cerebrais, o equilíbrio e a degeneração (doenças), além da comparação feita com os demais seres vivos existentes no ambiente.

Compreende-se a caracterização do ser humano e do ambiente a partir da organização de células (membrana plasmática, citoplasma e material genético), dos organismos unicelulares e pluricelulares bem como a manutenção e evolução das espécies e o processo reprodutivo dos seres seja ele sexuais ou assexuais,

Destacam-se alguns aspectos fundamentais, como processos assexuais ou sexuais, existência de células especializadas para a reprodução (gametas), fecundação interna ou externa ao corpo, as várias formas de proteção para o desenvolvimento do embrião e o cuidado dos pais com os descendentes jovens, localizando-se o ser humano nessas discussões (BRASIL, 1998, p. 106).

A partir daí, verifica-se a sequência didática dos conceitos acerca da reprodução humana e das mudanças hormonais ligadas ao amadurecimento sexual denominada puberdade. De acordo com os PCNs (1998), estas mudanças devem ser trabalhadas com os adolescentes a fim de esclarecer as eventuais dúvidas sobre a temática, contribuir para o desenvolvimento saudável e preservação da saúde. Pois, estes assuntos estão intimamente ligados à gravidez, aos métodos contraceptivos, contribuindo para a prevenção de infecções sexualmente transmissíveis.

Portanto, no que se refere a sexualidade, os PCNs afirmam que

[...] as informações devem ser claras e objetivas combatendo preconceitos que atrapalham o desenvolvimento e valorizando o respeito ao próprio corpo, às vontades e às dúvidas, bem como o respeito ao corpo e aos sentimentos dos parceiros [e das parceiras], na perspectiva do respeito mútuo e da convivência solidária (BRASIL, 1998, p. 106).

Sendo assim, muitos são os aspectos citados nos PCNs que devem ser levados em consideração para formação do ser humano nas diferentes áreas e nos diferentes setores da sociedade. O ser humano no aspecto biológico, social, cultural, as relações 
interpessoais, nas relações entre o sujeito e a família, o grupo de amigos, o desenvolvimento de aspectos éticos para a sua atuação na sociedade como cidadão crítico.

\section{Metodologia}

Esta pesquisa tem natureza empírica, que se fundamenta teórica e conceitualmente nos campos da Educação em Ciências e Psicologia da Educação. Assumiu ainda, caráter descritivo no objetivo de analisar o conteúdo da fala de 38 estudantes acerca da sua formação humana de conhecimentos, valores e atitudes sobre a preservação da sua saúde e bem-estar físico, mental e relacional.

Para alcançar o objetivo da pesquisa, os dados da pesquisa foram coletados por meio do Grupo Focal, com as falas gravada em áudio, a partir da assinatura do Termo de Consentimento livre e Esclarecido pelos pais ou responsáveis. Foi escolhido um grupo de estudantes bem específicos da localidade: alunos regularmente matriculados no $9^{\circ}$ ano do Ensino Fundamental de uma escola pública estadual no município de Porto Nacional, Tocantins, para formar dois grupos focais com 19 alunos em cada um deles.

Em relação à composição dos grupos, foram homogêneos nos contextos de vida dos participantes, mas não necessariamente em atitude. De acordo com Flick (2013), a chave para as comparações que serão feitas com os dados está na forma de como a amostragem será determinada, em que a escolha de uma amostragem qualitativa reflete a diversidade dentro do grupo ou população sob estudo.

O interesse pelo grupo focal como instrumento para coleta de dados, se dá na medida em que "comparado à entrevista individual, se ganha em relação à captação de processos e conteúdos cognitivos, emocionais, ideológicos, representacionais” (GATTI, 2005, p. 10). As interações que ocorrem no grupo têm seu foco ampliado, propiciando a possibilidade de observar o processo em ação nas trocas entre os participantes, reações individuais e coletivas, no intercâmbio de opiniões.

Importa-nos salientar que no grupo focal a unidade que está sendo analisada é o próprio grupo. De modo que posicionamentos, opiniões e ideias mesmo que não seja unanimidade, para efeito de análise, interpretação e discussão dos resultados, serão referidos como do grupo (GONDIM, 2002).

Há cinco pressupostos que adotamos neste trabalho: 
(1) que as pessoas são uma fonte valiosa de informações, incluindo informações sobre si mesmas; (2) que as pessoas podem dar respostas sobre elas mesmas, e são suficientemente articuladas para verbalizar seus pensamentos, sentimentos e comportamentos; (3) que as pessoas precisam de ajuda para 'minerar' essa informação, um papel desempenhado pelo entrevistador, ou pesquisador, que 'concentra' a entrevista no grupo focal entrevistado; (4) que a dinâmica no grupo pode ser usada para trazer à tona informações genuínas em vez de criar um fenômeno de 'pensamento de grupo'; e (5) que a entrevista do grupo é superior à entrevista de uma pessoa individualmente (LEDERMAN, 1990, p. 118, tradução nossa) ${ }^{1}$.

Os grupos de discussão tiveram como eixos norteadores, 6 questionamentos:

Pergunta 1: O que você vê quando se olha no espelho?

Pergunta 2: O que é sim ou não em relação ao seu corpo?

Pergunta 3: Quem você procura quando precisa de conselho/orientação?

Pergunta 4: Quais são suas referências de comportamentos certos e errados?

Pergunta 5: O que significa comportamento de risco na adolescência?

Pergunta 6: Qual o tipo de apoio vocês recebem na escola?

Após a coleta os dados passaram pela enumeração, em que foi adotada a presença de um elemento significativo como um indicador de sentidos a partir dos objetivos de análise. A enumeração foi seguida pela categorização composta por duas partes, o inventário e a classificação, isto foi necessário para que se garantisse a condição de exclusão mútua, a homogeneidade, a pertinência, a objetividade e a fidelidade e a produtividade.

Como método para a análise dos dados, foi utilizada a Análise do Conteúdo de Laurence Bardin (2016), e a intenção com isso foi trazer à compreensão da fala dos estudantes, concebendo a linguagem como transparente.

Franco (2018) indica três pressupostos para a análise dos dados: $a$. Cada mensagem, seja ela escrita, oral ou mesmo sensorial, tem, potencialmente, grande quantidade de informações sobre quem a originou. No que se referem às suas crenças, concepções de mundo, "interesses de classe, traços psicológicos, representações sociais, motivações, expectativas etc.” (FRANCO, 2018, p. 25); b. O conteúdo da mensagem 
é selecionado pelo autor a partir de referenciais sociais nos quais se encontra inserido, em que podemos incluir a Educação como prática social; $c$. A teoria exposta orienta a concepção de realidade (consciente ou ideologizada) do autor, e esta "[...] é filtrada mediante seu discurso e resulta em implicações extremamente importantes, para quem se propõe fazer análise de conteúdo” (FRANCO, 2018, p. 26).

Foram realizadas três etapas, estabelecidas por Bardin (2016): Pré-análise, que buscou a operacionalização e sistematização das ideias, através da elaboração de um esquema do desenvolvimento das operações sucessivas, sendo assim, objetivou a organização; a Exploração do Material, que consistiu em operações de codificação, descontos e enumerações; e o Tratamento dos Resultados, Inferências e Interpretação, que é onde os resultados brutos foram tratados de maneira a seres significados e validados.

Por meio da Inferência e Interpretação que os conteúdos mais aprofundados da fala dos estudantes foram identificados e compreendidos.

O conteúdo foi codificado tendo como Unidade de Registro a unidade não gramatical “O Tema” (BARDIN, 2016, p. 105). Sua escolha se justifica por ser considerada a mais útil unidade de registro, quando se trata de análise de conteúdo, assim como a possibilidade de analisar documentos inteiros, ou partes, para determinar valores, crenças, atitudes, entre outros. Sobre isso, Franco (2018, p. 42) afirma que uma

[...] questão temática incorpora, com maior ou menor intensidade, o aspecto pessoal atribuído [...] acerca do significado de uma palavra e/ou sobre as conotações atribuídas a um conceito. E, isso, com certeza, envolve não apenas componentes racionais, mas também ideológicos, afetivos e emocionais.

Assim, a investigação da fala dos estudantes, a partir de uma multiplicidade de perspectivas, implica no entendimento do contexto e na descrição da "[...] estrutura lógica das expressões, verificando as associações, denotações, conotações [...]” (KRIPPENDORFF, 1990, p. 30).

Por fim, na fase de inferência, a análise teve como eixo as significações que a mensagem forneceu, considerou-se com isto os aspectos legais da Educação em Ciências, os fundamentos psicológicos do desenvolvimento humano, bem como a perspectiva da educação para formação humana. 


\section{Análise e discussão}

\section{Autoimagem, autoestima e fatores de variação}

Esta categoria tem como temática a articulação de fatores biológicos e socioculturais na composição, tanto das percepções, quanto dos comportamentos em resposta aos estímulos do meio. $\mathrm{O}$ excerto abaixo apresenta essa ligação:

Eu vejo uma pessoa que terá um futuro brilhante! Um futuro muito brilhante pela frente! Eu acredito em mim mesma! Quando eu olho em mim mesma, eu vejo que eu tenho que ter confiança cada dia mais em mim, né?! Porque no mundo em que nós estamos vivendo é difícil ter confiança. E a primeira característica de ser uma pessoa tem um bem-estar é acreditar em si própria. (Grupo Focal 1).

Para autoimagem, a pesquisa se deparou com uma alta frequência da temática imagem corporal como definidora da adolescência, o que aponta para uma conexão comum, uma vez que, grande parte da literatura existente aponta para essa vinculação do período com a imagem corpórea (SHAFFER; KIPP, 2012; PAPALIA; FELDMAN, 2013).

No entanto, apesar da expressão positiva de aceitação, o conteúdo da fala dos estudantes segue opondo-se a uma linearidade. A autoimagem ganha uma variação de acordo com o humor e este, interfere na autoestima. As falas abaixo trazem essa indicação:

É, depende do dia né? Porque tem aquele dia que você fala: menina, eu tô precisando dar uma ajeitada na sobrancelha.

Fica estressada... Eu, quando eu tô assim, eu não quero muito estar comigo não... Dá uma preguiça de se arrumar. (Grupo Focal 2).

As indicações desse conteúdo são de que a autoimagem declarada corresponde a perspectiva do desenvolvimento biopsicossocial, assim como aponta Cavalcanti (1988), isto porque ela abrange alterações corporais, atitudinais, emocionais, que em interação com o meio social, tanto a forma como ele se vê, quanto a forma como encara realidade pode ser modificada.

Nesta categoria, a visão sobre o corpo tem variações de humor e estados de ânimo inconstantes, conteúdo de fala corroborado por Aberastury e Knobel (1971), que em seus dez aspectos essenciais para caracterizar a adolescência, ainda acrescenta outros aspectos, “[...] 7) Flutuações de humor e do estado de ânimo; 8) Contradições no seu 
modo de pensar e agir onde, desta forma, a elaboração de lutos ditos normais nesta fase do desenvolvimento é facilitada [...]” (ABERASTURY; KNOBEL, 1971, p. 53).

A percepção dos grupos focais sobre os diferentes processos de produção de feminilidade e masculinidade, também emergiu como fator indicador do desenvolvimento da autoimagem. Quando indagados sobre a sua autoimagem, meninas e meninos foram enfáticos ao responderem que o gênero é determinante das capacidades individuais, das suas possibilidades de fazer e poder fazer.

Especificamente para as meninas, as consequências da variação hormonal são introduzidas como parte da temática e compõem o argumento multifacetado da concepção da autoimagem. A oscilação acontece, por exemplo:

Quando tá com cólica... A gente fica mais estressada. (Grupo Focal 2).

Segundo os estudantes e as estudantes dos grupos, a autoimagem dos meninos não está sujeita as alterações a que as meninas declaram estar. O conteúdo desta unidade de análise é de que para os meninos, no ambiente escolar, há menos preocupações com a aprovação cotidiana sobre aparência física e manutenção do bom humor.

E por isso, ainda segundo o conteúdo da fala dos meninos dos grupos focais, a dependência do humor para se significar e vivenciar bem-estar direcionando seu comportamento perante os pares, é declarado inexistente:

Eu nunca tô triste. (Grupo Focal 1).

Essa fala é justificada pelos membros femininos dos grupos, quando generalizam a partir do comportamento de um colega, conforme excerto:

É verdade, professora. Esse menino faz a gente rir.

A gente pode estar num dia fracassado. (Grupo Focal 1).

A categoria nos leva a referência ao campo do Ensino de Ciências e aos seus objetivos de ensino. Esses fatores de variação da autoimagem e autoestima referidos na categoria devem ser atendidos e problematizados no $9^{\mathrm{a}}$ ano, a partir do princípio proposto nos PCNs - o da reconstrução de uma consciência social que ultrapasse as questões ambientais e da natureza de forma isolada, levando o aluno a “[...] perceber a vida humana, seu próprio corpo, como um todo dinâmico, que interage com o meio em sentido amplo, pois tanto a herança biológica quanto as condições culturais, sociais e afetivas refletem-se no corpo” (BRASIL, 1998, p. 22). 
Por se tratar de um estudo voltado a disciplina de Ciências, ou ainda as diversas formas de se criar conexão entre ela e os acontecimentos da vida, como forma de tornar real o conteúdo a ser ministrado nas aulas, dentro do processo educativo, é necessário lembrar que, de acordo com o que formaliza os PCNs (1998), apresentam conceitos acerca do ser humano e da saúde para que assim os professores possam compreender e ter como base as orientações citadas neste para preparação de suas aulas.

Nesse caso, os PCNs (1998) apresentam algumas propostas que possam explicar os assuntos atuais e relevantes sobre a instrução e o desenvolvimento do ser humano, que já mencionado neste estudo, nas suas diferentes fases, para que este seja capaz de preservar sua saúde e entender as funções de cada parte do seu corpo. Propõe a criação de folhetos, textos coletivos, comunicação de informações, a apresentação de tabelas, atlas anatômicos, experimentos e simulações, entre outros. Valendo, portanto, que se lance mão de recursos pedagógicos capazes de levar ao estudante adolescente conteúdos que favoreçam a compreensão das transformações biológicas e emocionais que ele passa.

Possibilitando assim que ele se conheça e reconheça as suas respostas aos estímulos do meio, as transformações corpóreas e a interação com as organizações sociais e familiares, na tentativa de tornar esse período o menos traumático possível.

\section{Assimetria do lugar social do corpo Adolescente}

Esta categoria emergiu do tema assimetria dos lugares que os corpos de meninos e meninas devem ocupar na sociedade, separadamente.

Em diversas falas do grupo focal as meninas são vistas como objeto de desejo. Esse campo de debate lança-se mão de Foucault (1988), no que este se refere as relações de poder. Para o autor, o corpo dentro de uma estrutura de poder, não é capaz de se encontrar em posição de exterioridade relativo a outros tipos de relação, (processos econômicos, relações de conhecimentos, relações sexuais), no entanto, estas relações lhes são próximas, produzindo efeitos instantâneos das partilhas executadas pelo sujeito, provocando desigualdade e desequilíbrios, estas condições internas. Assim as relações de poder são as superestruturas, capazes de exercer o papel proibitivo, de cerceamento, ou redução, continuamente produzindo este efeito (FOUCAULT, 1988). 
Com base nisso, levanta-se a questão do corpo adolescente feminino como elemento culturalmente afastado do poder, em relações assimétricas, evidenciadas nos comportamentos vivenciados no cotidiano, quase um não lugar. O excerto a seguir, traz um recorte do conteúdo das falas das meninas do Grupo Focal 1:

O caso é que para mulher já é discriminante... Que hoje em dia fala que mulher é rapariga... Já pro homem não, é como se fosse normal. Mas se chegar e vê uma menina na conversa... Ali é uma coisa errada... Tão ficando... Tão fazendo alguma coisa de errada... É muito difícil essa vida, gente.

É porque as pessoas olham pro lado das mulheres, por exemplo no caso de cinco homens e uma mulher, já olham com olho de julgo (sic)... Aí já falam: Aquela menina tá lá, é porque ela tá com interesse em algum, é uma puta, é uma rapariga... Usam esse nome feio... Já o homem não... É galanteador... É garanhão. Já olha diferente. (Grupo Focal 1).

Para as meninas, toma-se aqui a liberdade de nomeá-las, também assim, o fato de se ver como objeto de desejo do outro, é uma situação que embora culturalmente normatizada, pode ser uma dificuldade, e fator de estresse elevado e interferência direta a sua autoimagem.

Nesse panorama relativo ao corpo da adolescente, a temática emerge ainda, o sentimento de inferioridade em relação ao seu par oposto, o corpo masculino. Os excertos trazem as falas sobre as proibições feitas ao corpo feminino.

Tirar a camiseta no meio do povo...

Mulher faz isso também...

Mulher não faz... Homem já faz... Se um homem tem um físico bonito já sai elogiando, agora se uma mulher tira a camiseta é um absurdo. (Grupo Focal 1).

O que de fato se tornou explícito na fala dos grupos focais, foi o quanto a questão de gênero influencia diretamente para a realização de determinada ação, como citado nesse excerto onde a estudante denota $o$ ato de tirar a blusa uma ação normal para pessoas do sexo masculino e para o feminino se torna vulgar. Diante disso, denotamos uma questão de lugar social do corpo feminino já que ele é visto como objeto de desejo sexual.

Relevante também é a relação adolescente com o corpo, com o que gera satisfação e completude das suas medidas e aparência, posta na vinculação: juventude e estética. Segue um argumento que ilustra essa questão:

Tinha uma menina que estudava com a gente, que tinha o corpo ideal e emitia felicidade por onde ela passava, mas ela saiu da escola. (Grupo Focal 2). 
De acordo com os grupos focais, o bem-estar é ligado diretamente com a aparência, o estar bem é sinônimo de idealização, já que a cultura define a mulher como um ser social inconstante. Isto porque existe um culto narcísico ao corpo, uma sobrevalorização do físico e, como consequência, vai surgir uma desvalorização das capacidades psicológicas e cognitivas do sujeito. Atingir o corpo ideal, atingir as medidas perfeitas, é o novo objetivo para o adolescente na sociedade contemporânea que cada vez mais impõe modelos de beleza, impactando significativamente no desenvolvimento de sua personalidade (AGUIAR, 2014).

A assimetria também se apresentou no conteúdo de experimentações, tais como bebida, jogo e relações amorosas. Novamente, o desequilíbrio das consequências é argumentado e naturalizado - aos meninos é permitido, já às meninas, há a naturalização dos riscos de estupro e gravidez indesejada.

Nas falas dos grupos, emerge uma clara diferenciação entre os tipos de violência/ riscos para os dois gêneros, as meninas associam inevitavelmente a violência de gênero, ao consumo de bebidas e outras drogas, a quem sentem as vezes dificuldade em verbalizar, há claramente um comedimento das meninas relativo aos tipos e classificação das violências/riscos, mesmo que esse comportamento possa ser um afloramento individual.

A partir dessas análises, abre-se o entendimento de que a escola e os seus currículos poderiam contribuir sobremaneira para a compreensão expandida destas situações, sobretudo na disciplina de Ciências. Segundo os PCNs (1998), compete ao docente, mediar tanto o estudo do cérebro humano, quanto "[...] o campo dos comportamentos, das emoções, da formação dos hábitos e de outras questões subjetivas, ligadas aos valores, de modo ainda mais evidente que em outros estudos do ser humano" (BRASIL, 1998, p. 104).

Para esse aspecto relativo aos comportamentos desencadeados em função do reconhecimento de um corpo em transformação, ao ainda, da aparente falta de habilidade em lidar com essas transformações, como ficou bastante evidente no contato com o grupo focal, assim sendo, é necessário estabelecer vínculo com o que determinam os PCNs. Compreendendo que grande parte da percepção relativa ao corpo se dá como resposta a sua relação com indivíduos que passam pelas mesmas transformações e em um ambiente que os coloca em relação direta sempre, também por se entender que é no cérebro que se processa grande parte das transformações para formar o indivíduo, faz-se necessário que o docente de Ciências então, promova 
mediações sobre o desenvolvimento do cérebro humano e suas implicações maturacionais no comportamento social (BRASIL, 1998; PAPALIA; FELDMAN, 2013).

Evidencia-se a importância do esclarecimento das transformações biológicas e sociais aos jovens, pois, diferente do que se acreditava no início do século passado, que na puberdade o cérebro já havia se desenvolvido totalmente, na atualidade os estudos apontam que essas transformações continuam se processando em forma severa nas estruturas cerebrais em envolvimento às emoções, relativo ao julgamento, organizando o pensamento e desenvolvendo mecanismos de autocontrole, essas se processam até a idade adulta (PAPALIA; FELDMAN, 2013).

\section{valor da fonte segura na tomada de decisão}

Nesta categoria evidencia-se claramente a falta de fontes seguras para a tomada de decisão. Diversos estudantes alegaram se basear na decisão por experimentação pela falta dessa fonte.

Identificou-se aspectos relativos ao meio e atitudes apresentadas por pessoas como fatores influenciadores no comportamento do adolescente. Os conteúdos que remeteram as atitudes apresentadas, comportamentos que sofrem influência de figuras e representações capazes de oferecer suporte as decisões dos adolescentes.

Isto posto, leva a compreensão de que um suporte emocional é algo representativo nesta fase da vida. $\mathrm{O}$ excerto abaixo, resposta à pergunta da mediadora do grupo focal (Mas quem, fora a sua mãe?), ilustra exatamente o que torna essa busca por uma tomada de decisão imprecisa, já que as fontes não são seguras ou muitas das vezes não possuem fontes.

Tipo... Um professor, um vizinho, quando é mais velho e que já passou pelo mesmo problema que eu...

E vai saber me orientar né? Vai saber me explicar a situação, de como sair e... é isso. Um amigo também. (Grupo Focal 1).

De acordo com esse excerto, evidencia-se que os laços afetivos e de relacionamento podem ser facilitados com o tipo relação estabelecida em grupo ou individualmente. $\mathrm{Na}$ frequência desta unidade de análise, em ambos os grupos, emergiu as diferenças entre pesos dos laços de fontes seguras para meninos e para meninas, em diferentes momentos, conduzida nas falas. Para as meninas, estes laços têm peso diferente do que tem para os meninos, é antes uma caracterização diferenciada, sendo que nos 
grupos focais, notou-se uma inclinação das jovens para figuras maternas, tias, avós, ou figuras femininas. A fala do grupo denota professores como uma alternativa de fonte para tomada de decisão.

Os meninos buscam, como ficou evidente nos grupos focais, o pai, ou figura masculina representativa, capaz de cumpri esse papel. Sobre isso, a pesquisadora indaga sobre quais figuras representativas eles buscam como fonte de autorrevelação, ao que os grupos respondem que apenas os amigos.

Evidenciou-se, no entanto, falas sobre a escola como um lugar que não possui fontes seguras para tomada de decisões. Na frequência deste tema, os estudantes declaram que a escola não é um lugar de adolescer, que é um período segundo eles, difícil, de enfrentamento e que traz, segundo a fala dos grupos:

[...] medida de tristeza diária. (Grupo Focal 2).

Para este ambiente, as críticas foram duras e consideráveis, por se constituir um espaço que por força de origem deveria oferecer segurança e conforto aos adolescentes, no entanto classificado como hostil. Ou seja, um não lugar de fala dos adolescentes. $\mathrm{O}$ excerto a seguir ilustra uma sequência da fala dos adolescentes a respeito da falta de orientação educacional no âmbito escolar, em resposta à pergunta da pesquisadora:

Existe ou não existe? A colega disse que existe... mas vocês se sentem à vontade para expor problemas, dúvidas? (Pesquisadora).

Pra mim não.

Tem muitas coisas que tipo... ‘Eu não quero conversar com ela, nem com alguma pessoa da minha família', aí eu vou procurar um professor que eu confio.

Eu não gosto de falar... (Grupo Focal 1).

Você não gosta de falar? (Pesquisadora).

Não, não falo não.

Não é em todos os professores que eu confio.

Raramente...

E quando a escola fala, reduz a adolescência a puberdade ou trata da temática, bulliyng, depressão etc., com impessoalidade.

Já falaram aqui, mas... Alguns professores não gostaram não. Porque nós ficamos comentando depois, depois da aula que a gente teve sobre puberdade, ficamos comentando... Porque a gente foi gostando do assunto, tinham muitas dúvidas... (Grupo Focal 1). 
Estes argumentos vêm complementar o raciocínio de que a escola que poderia ser um campo de confiança para o adolescente, mas paradoxalmente não cumpre esse papel:

Ah, entendi! [...] A escola é um lugar seguro para conversar sobre essas questões adolescentes? (Pesquisadora).

Não... Não...

Nem todas...

Nem sempre...

Nenhuma vez... (Grupo Focal 1).

De acordo com o excerto, a escola trata de temáticas mensais com impessoalidade e os estudantes possuem necessidades diárias e pessoais, buscam apoio escolar e ela não possui profissionais adequados para tratar esse tipo de temática. Os alunos sentem necessidade desse apoio, conforme ilustra o excerto que segue:

[...] não é lugar de escuta do adolescer. Não há profissional que atenda às necessidades pessoais diárias [...] (Grupo Focal 2).

Cabe evidenciar o espaço da escola como aspecto importante da pesquisa. Como um dos locais privilegiados do adolescer, pela sua excessiva permanência neste em um dos períodos da vida mais importante para a formação da personalidade, é importante que se traga para essa reflexão,

[...] considerando as vertiginosas mudanças que se estabelecem no funcionamento da sociedade, convém questionar se o comprometimento do processo educativo especialmente do aluno adolescente, o que se oculta, na verdade é a inatividade e a indolência em se buscar intervenções mais apropriadas aos impasses que se apresentam nas diversas instituições sociais na atualidade, entre elas a escola. (OLÍMPIO; MARCOS, 2016, p. 500).

A negligência da dimensão do adolescer, coloca esses jovens sob o peso de uma atmosfera carregada de preconceito e incompreensão, que gera sofrimento e desacertos relativo a decisões que precisam ser tomadas neste período da vida.

Os grupos focais denunciaram a ausência de envolvimento real da escola com o período de desenvolvimento que os adolescentes estão experimentando, o que permite-nos questionar de que maneira a formação docente e a própria prática docente são suficientemente significativas para contribuir nas ações educativas de: desenvolvimento físico (questões relativas à saúde, questões físicas, sexualidade e 
reprodução), desenvolvimento cognitivo (esquemas de organização de pensamento e raciocínio moral), ainda especificamente, da cognição social no âmbito biológico-social-histórico das mudanças identidade, comportamento sexual e relacionamentos fraternais e amorosos.

\section{Conclusão}

Essa pesquisa teve como objetivo geral, analisar na perspectiva fenomenológica, conhecimentos, valores e atitudes na adolescência a partir do conteúdo da fala de estudantes, relacionando-os ao Ensino de Ciências.

Compreende-se assim a dificuldade de delimitação do tema e a necessidade de repensar, estudar e pesquisar mais sobre a adolescência e as transformações sócio históricos, psicológicas, sociais, biológicas e culturais que implicam seu desenvolvimento. Emergiram três categorias pela frequência da unidade de análise tema. Valendo-se da Análise de Conteúdo, identificou-se a primeira categoria, nomeada de Autoimagem, autoestima e fatores de variação, na qual o fator gênero é tomado como referência para indicar as variações de autoimagem e autovalor atribuídos a si mesmos, sendo naturalizadas os significados culturais de imagem corporal e oscilação de humores como inerentes a imagem de meninos equilibrados e de meninas desequilibradas e inconstantes. Na categoria nomeada como Assimetria do lugar social do corpo adolescente, existe uma autoavaliação da aparência física com correspondências aos arbítrios culturais de beleza e de ideal do corpo, incidindo sobre os valores e julgamentos sobre si, podendo gerar sentimentos de inadequação pela não correspondência as expectativas do modelo dominante. Nesta categoria os estudantes articularam que o corpo feminino ocupa lugares inferiores ao masculino, tratando assim de uma questão de gênero. Diante dessas considerações, notamos o objeto idealizado é o corpo perfeito para gerar bem-estar. Identificou-se na terceira categoria, que a escola não trata de temas ligados a adolescência e não possui fonte segura para orientação, além disto, no meio familiar os estudantes articularam que não consideram uma boa fonte para tomadas de decisão.

É evidente que nesta pesquisa os estudantes destacaram a todo momento o desejo de ter uma referência segura de tomada de decisão no âmbito escolar e que as experiências das ações escolares trazem medidas de tristeza, como depressão, bullying e suicídio. Considerando as produções de sentido que movimentam crenças 
sobre valores humanos, perspectivas políticas e religiosas da contemporaneidade, presentes no ambiente escolar, cabe a reflexão: Esse período deve ser baseado somente nesses adjetivos ou cabe ao professor de Ciências, juntamente com a escola, mudar essa realidade?

Considerando-se que cada jovem tem seu tempo e forma de desenvolvimento, sua construção social, física e cognitiva é de suma importância o acompanhamento e orientação, o comportamento do jovem reflete sua relação com os pais, o grupo de amigos, com a sociedade e principalmente consigo mesmo. E nesse sentido, qual tem sido o movimento profissional docente, no Ensino de Ciências, sobre adolescência para as estudantes e estudantes em sua multidimensionalidade? E nisto, em que medida a educação como prática social intersecciona outros agentes educativos (comunidade escolar, gestão, conselhos etc.)?

É possível perceber então a forma como os fatores biológicos e sociais influenciam na formação pessoal, cognitiva, educacional e até mesmo profissional dos jovens desde a infância, passando pela adolescência e a vida adulta.

Por fim, entende-se que a temática é de extrema importância e que a indagação é contínua, para compreensão da formação do adolescente em diferentes aspectos, para construir um indivíduo com norteamentos melhores para essa fase, o adolescer.

\section{Adolescing in body, mind and affection: a study on developing values and attitudes from science teaching}

\section{Abstract}

The National Curriculum Parameters (NCP) of the Third and Fourth Cycles of Elementary Education in Natural Sciences refer to educational actions that signify adolescence considering the necessary interaction between the organic brand, puberty, and the culturally and socially produced senses on the body and identity at this stage of human development. Teaching in Sciences implies the relational construction of knowledge, values and attitudes for an adolescent who responds to the demands on himself, in a critical, cognitive, and affective way, to maintain body integrity, reproductive health, and sexual behavior. This research aimed to analyze the scope of actions and practices in Science Education in adolescence based on the content of the speech of 9th grade students. For this, it was used as a method of data collection, the Focus Group and as an analysis tool, the Content Analysis proposed by Bardin. Three categories emerged: in the first, the gender factor is taken as a reference to indicate the variations of self-image and self-value attributed to themselves by adolescents; in the second, self-assessment of physical appearance is related to the cultural standards of beauty and ideal of the body, falling on its values and judgments, potentiating feelings of inadequacy due to non-correspondence to the expectations of the 
predominant model; and the third, indicates the absence of a reliable source at the school for decision making. The research concluded, in this context, that the school is not a place of speech for the adolescent, because it deals with themes related to adolescence with impersonality, focusing on the biological bias of puberty and neglecting the psychosocial, emotional and cultural issues that adolescents demand.

Keywords: adolescence; culture; Science Education; puberty; subjectivity.

\section{Nota}

1 (1) that people themselves are a valuable source of information, including information about themselves; (2) that people can report on and about themselves, and that they are articulate enough to put into words their thoughts, feelings and behaviors; (3) that people need help in "mining" that information, a role served by the interviewer, or researcher, who "focuses" the interview in the focus group interview; (4) that the dynamics of the group can be used to surface genuine information rather than creating a "group think" phenomenon; and (5) that the interview of the group is superior to the interview of an individual.

\section{Referências}

ABERASTURY, A.; KNOBEL, M. Adolescência normal. Buenos Aires: Editorial Paidós, 1971.

AGUIAR, S. F. A. de. O meu corpo e eu: a imagem corporal e a auto-estima na adolescência. Lisboa: ISPA, 2014. Dissertação de Mestrado em Psicologia Clínica, Instituto Universitário Ciências Psicológicas, Sociais e da Vida, 2014. Disponível em: <http://repositorio.ispa.pt/bitstream/10400.12/5028/1/18268.pdf>. Acesso em: 21 Out. 2019.

AMARAL, V. L. do. Psicologia da Educação. Natal: EDUFRN, 2007.

ARIÈS, P. História Social da Criança e da Família. Rio de Janeiro: Livros técnicos e científicos, 1981.

BARDIN, L. Análise de Conteúdo. São Paulo: Edições 70, 2016.

BEE, H.; BOYD, D. A criança em desenvolvimento. 12 $2^{\mathrm{a}}$ ed. Porto Alegre: Artmed, 2011.

BRASIL. Parâmetros Curriculares Nacionais (PCNs). Ciências Naturais. Terceiro e Quarto Ciclos. Brasília: MEC/SEF, 1998.

CALHEIROS SANTOS, K. M.; ZANOTTI, S. V. Adolescência e Corpo: Ideais contemporâneos? POLÊM!CA, v. 12, n. 4, p. 809-820, 2013. Disponível em: <https://www.e-publicacoes.uerj.br/ index.php/polemica/article/view/8650/6534>. Acesso em: 10 Set. 2019.

CAMPOS, D. M. de S. Psicologia da Adolescência: Normalidade e Psicopatologia. $24^{a}{ }^{\mathrm{a}}$ ed. Petrópolis: Vozes, 2012.

CAVAlCANTI, R. C. Adolescência. In: VITIELlo, N. (Ed.). Adolescência hoje. São Paulo: Roca, 1988. p. 5-27.

CERQUEIRA-SANTOS, E.; MELO NETO, O. C. de; KOLLER, S. H. Adolescentes e adolescências. In: HABIGZANG, L. F.; DINIZ, E.; KOLLER, S. H. (Ed.). Trabalhando com adolescentes: teoria e intervenção psicológica. Porto Alegre: Artmed, 2014. p. 17-29. 
EATON, D. K. et al. Youth risk behavior surveillance-United States, 2007. Morbidity and Mortality Weekly Report, v. 57, n. 4, p. 1-131, 2008.

ECCLES, J. S.; WIGFIELD, A.; BYRNES, J. Cognitive Development in Adolescence. In: LERNER, R.; EASTERBROOKS, A.; MISTRY, J. (Ed.). Handbook of Psychology. Hoboken, NJ, USA: John Wiley \& Sons, Inc., 2003. Disponível em: <https://doi.org/10.1002/0471264385.wei0613>.

FLICK, U. Introdução à metodologia de pesquisa: um guia para iniciantes. Porto Alegre: Penso Editora, 2013.

FOUCAULT, M. História da sexualidade I: A vontade de saber. Rio de Janeiro: Edições Graal, 1988.

FRANCO, M. L. P. B. Análise de Conteúdo. Brasília: Líber Livro Editora, 2018.

GATTI, B. A. Grupo focal na pesquisa em ciências sociais e humanas. Brasília: Líber Livro Editora, 2005.

GONDIM, S. M. G. Perfil profissional e mercado de trabalho: relação com formação acadêmica pela perspectiva de estudantes universitários. Estudos de Psicologia, Natal, v.7, n. 2, 2002.

KOHLBERG, L. Psicología del desarrollo moral. Bilbao: Desclée de Brouwer, 1992.

KOSTANSKI, M.; FISHER, A.; GULLONE, E. Current conceptualisation of body image dissatisfaction: have we got it wrong? Journal of Child Psychology and Psychiatry, v. 45, n. 7, p. 1317-1325, out. 2004. Disponível em: <https://doi.org/10.1111/j.1469-7610.2004.00315.x>.

KRIPPENDORFF, K. Metodologia de análisis de contenido: teoria e práctica. Barcelona: Ediciones Paidós, 1990.

KUHN, D. Do Cognitive Changes Accompany Developments in the Adolescent Brain? Perspectives on Psychological Science, v. 1, n. 1, p. 59-67, 24 mar. 2006. Disponível em: <https://doi. org/10.1111/j.1745-6924.2006.t01-2-.x>.

LEDERMAN, L. C. Assessing educational effectiveness: The focus group interview as a technique for data collection 1. Communication Education, v. 39, n. 2, p. 117-127, abr. 1990. Disponível em: <https://doi.org/10.1080/03634529009378794>.

MAHONEY, A. A. Introdução. In: MAHONEY, A. A.; ALMEIDA, L. DE R. (Ed.). Henri Wallon: Psicologia e Educação. 10ª ed. São Paulo: Editora Loyola, 2010. p. 9-18.

MEAD, M. O conflito de gerações. Lisboa: Dom Quixote, 1970.

OLÍMPIO, E.; MARCOS, C. M. A escola e o adolescente hoje: considerações a partir da psicanálise. Psicologia em Revista, v. 21, n. 3, p. 498, 13 jul. 2016. Disponível em: <http://periodicos. pucminas.br/index.php/psicologiaemrevista/article/view/P.1678-9523.2015V21N3P498>. Acesso em: 15 Jul. 2019.

OLIVEIRA, D. A. da S. Autoconceito, Autoestima e Rendimento Académico em Alunos do $1^{\circ}$ ano de Escolaridade nos Cursos de Ciências e Tecnologias e Cursos Profissionais. Porto: UFP, 2015. Dissertação de Mestrado em Psicologia da Educação e Intervenção Comunitária, Faculdade de Ciências Humanas e Sociais, Universidade Fernando Pessoa, 2015. Disponível em: <https://bdigital.ufp.pt/bitstream/10284/5014/1/DM_DianaOliveira.pdf>. Acesso em: 07 Set. 2019.

PAPALIA, D. E.; FELDMAN, R. D. Desenvolvimento Humano. 12ª ed. Porto Alegre: AMGH, 2013. 
PIAGET, Jean. Epistemologia genética. 4ª ed. São Paulo: Martins Fontes, 2012.

PRESNELL, K.; BEARMAN, S. K.; STICE, E. Risk factors for body dissatisfaction in adolescent boys and girls: A prospective study. International Journal of Eating Disorders, v. 36, n. 4, p. 389-401, dez. 2004. Disponível em: <http://doi.wiley.com/10.1002/eat.20045>.

SANTROCK, J. W. Adolescência. Porto Alegre: Artmed, 2014.

SHAFFER, D. R.; KIPP, K. Psicologia do Desenvolvimento: Infância e adolescência. $2^{\text {a }}$ ed. São Paulo: Cengage Learning, 2012.

SHAVELSON, R. J.; BOLUS, R. Self concept: The interplay of theory and methods. Journal of Educational Psychology, v. 74, n. 1, p. 3-17, 1982. Disponível em: <https://doi.org/10.1037/00220663.74.1.3>.

SILVA, M. C. R. da; VENDRAMINI, C. M. M. Evidências de validade de uma escala de autoconceito académico em estatística. Educação Matemática Pesquisa, v. 8, n. 2, p. 177-196, 2006. Disponível em: <http://ken.pucsp.br/emp/article/view/459/385>. Acesso em: 10 Out. 2019.

STEVENS, A. Adolescência como sintoma da puberdade. Curinga, n. 20, p. 27-39, 2004.

STICE, E.; WHITENTON, K. Risk factors for body dissatisfaction in adolescent girls: A longitudinal investigation. Developmental Psychology, v. 38, n. 5, p. 669-678, 2002. Disponível em: <https://doi.org/10.1037/0012-1649.38.5.669>.

VAZ-SERRA, A. O auto-conceito. Análise Psicológica, v. 6, n. 2, p. 101-110, 1988. Disponível em: <https://repositorio.ispa.pt/handle/10400.12/2204>. Acesso em: 05 Jun. 2019.

WALLON, H. As origens do caráter na criança. São Paulo: Nova Alexandria, 1995.

YOUNGBLADE, L. M. et al. Risk and Promotive Factors in Families, Schools, and Communities: A Contextual Model of Positive Youth Development in Adolescence. Pediatrics, v. 119, n. Supplement 1, p. S47-S53, fev. 2007. Disponível em: <http://pediatrics.aappublications.org/lookup/ doi/10.1542/peds.2006-2089H>. Acesso em: 01 Abr. 2019. 